\title{
Flexural Strength of Glass Carbomer Cement and Conventional Glass Ionomer Cement Stored in Different Storage Media over Time
}

\author{
Muhammad Ali Faridi $^{a} \quad$ Abdul Khabeer $^{b}$ Saad Haroon ${ }^{c}$ \\ ${ }^{a}$ Department of Prosthodontics, Islamabad Medical and Dental College, Islamabad, Pakistan; ${ }^{b}$ Department of \\ Restorative Dental Sciences, College of Dentistry, Imam Abdulrahman Bin Faisal University, Dammam, Saudi Arabia; \\ 'Department of Restorative Dentistry, Lolwa Al-Mohannadi Medical Center, Al Khor, Qatar
}

\section{Significance of the Study}

- Glass ionomer cement has demonstrated low flexural strength. Recently, a biocompatible carbonbased additive has been used to supplement the cement, which, according to the manufacturer, improves the strength of the material. This study concluded that flexural strength of glass carbomer cement was similar to conventional glass ionomer cement. Therefore, its use should be limited to areas of minimal stress.

\section{Keywords}

Glass ionomer · Glass carbomer · Universal testing machine · Flexural strength

\begin{abstract}
Objectives: Glass ionomer cement (GIC) is routinely placed as a restorative material in dentistry. However, due to its poor physical properties, its use is limited to cases where the level of stress on restoration is minimal. Improved formulations of GIC have been developed to overcome these drawbacks. The purpose of this study was to evaluate flexural strength of a conventional GIC (Fuji IX) against a newly developed glass carbomer cement (GCP). Materials and Methods: For Fuji IX and GCP, a total of 80 blocks were prepared and divided into 16 groups $(n=5)$. These groups were further categorized according to the storage medium (artificial saliva and Vaseline) and time intervals ( $24 \mathrm{~h}$ and 1, 2, and
\end{abstract}

\begin{tabular}{ll}
\hline KARGER & ( 2018 The Author(s) Karger \\
Published by S. Karger AG, Basel Open caccess \\
E-Mail karger@karger.com & $\begin{array}{l}\text { This is an Open Access article licensed under the Creative Commons } \\
\text { Attribution-NonCommercial-4.0 International License (CC BY-NC) } \\
\text { (http://www.karger.com/Services/OpenAccessLicense), applicable to } \\
\text { the online version of the article only. Usage and distribution for com- } \\
\text { mercial purposes requires written permission. }\end{array}$
\end{tabular}

4 weeks). A 3-point bending test was carried out, and statistical analysis was done using ANOVA and Tukey post hoc tests. Results: Fuji IX showed a mean flexural strength of $25.14 \pm$ 13.02 versus $24.27 \pm 12.57 \mathrm{MPa}$ for GCP. There was no significant statistical difference between both materials when compared under storage media. Both materials showed the highest value for flexural strength at 2 weeks of storage and lowest at 4 weeks. Conclusion: The storage media do not affect the flexural strength of the specimens with reference to time. Time is the unique factor with relative influence on mean resistance to fracture. Further testing is required to evaluate the true potential of the newly developed GCP.

(c) 2018 The Author(s)

Published by S. Karger AG, Basel

Submitted to the University of Warwick in partial fulfillment of the requirements for the award of the MSc in Restorative Dentistry.
Abdul Khabeer

College of Dentistry, Imam Abdulrahman Bin Faisal University Room 3038

Dammam 31441 (Saudi Arabia)

E-Mail akhabz@ hotmail.com 


\section{Introduction}

In dentistry, operators have always encountered the common problem of replacing missing tooth structure by artificial materials with regard to both aesthetics and function restoration. The ability of the dentist to accomplish the desired result has been limited by certain basic factors such as the availability of suitable materials compatible with the hazards present in the oral cavity and the development of an appropriate process for their daily use. Ideally, a restorative material should have physical properties identical to those of the tooth and should also mimic it aesthetically [1]. During the first half of the 19th century, amalgam and gold were developed as viable restorative materials for dentistry [2]. However, their poor aesthetic properties led to the development of dental cement and more aesthetically acceptable restorative materials. Glass ionomer cements (GIC) were a step in this direction and have now become one of the most commonly used restorative materials in dental practice.

GIC are classified as acid-base cements. They are formed as a result of a reaction between weak polymeric acids and powdered glasses, with the final structure containing filler particles in the form of unreacted glass which helps in reinforcing the set cement [3]. Conventional GICs have been used in the oral cavity mainly due to their favorable properties such as the ability to bond to tooth structure, fluoride release, bactericidal ability, and the potential to promote remineralization [4]. However, despite these advantages, GICs are not considered as first-choice restorative materials like amalgam or resin composites. This is primarily due to the low compressive and flexural strength of GICs [5], which limits their use to cases where the level of stress on restoration is minimal. To overcome this drawback, improved formulations of GIC have been developed, mostly with the addition of resin [6]. Further improvement in the material has led to the development of glass carbomer cement (GCP) which incorporates nanosize particles with fluorapatite being added as a secondary filler [4]. The use of nanosize particles helps to increase the surface area for reaction of the cement leading to a better reactive process, while the inclusion of fluorapatite converts the glass ionomer into a fluorapatitelike material, as shown by Van Duinen et al. [7]. A biocompatible carbon-based additive has been used to supplement the cement, with the objective of improving the strength and transparency of the material [8]. Moreover, the fine structure of the cement gives it a smooth and highly polished surface similar to resin composite restorative materials.

Flexural Strength of a Newly Developed Glass Carbomer Cement
Flexural strength is a mechanical property of the material and can be defined as "the ability of the material to resist deformation under load" [9]. This study aimed to analyze the effects of different storage media and different time intervals on the flexural strength of GIC and the recently developed GCP. The hypothesis tested was that the flexural strength of GCP would be superior to conventional GIC with regard to different storage media and time intervals.

\section{Materials and Methods}

\section{Mold Preparation}

Silicone putty Zetaflow hydrophilic polysiloxane (Zehrmack Clinical, Badia Polesine, Italy) was used as the material of choice for the creation of molds $(2 \times 2 \times 25 \mathrm{~mm})$. The mold was created using a stainless-steel scaffolding to get the desired dimensions and allow easy removal once set, thus minimizing the risk of fracture. The scaffold also reduced the possibility of chipping the edges of the molds thus eliminating any chance of affecting the flexural strength of the specimens.

\section{Preparation of GIC Samples}

A chemically cured GIC (Fuji IX, Shade A3; GC International Corp, Japan) was provided in powder and liquid form (Table 1). Once the material was manipulated according to the manufacturer's instructions, it was placed in the silicone mold using a metalplastic instrument. The material was adapted to the surface of the mold with slight pressure. Compression firming was done by hand using a plastic instrument to allow proper adaptation of the material. The material was allowed to set for $160 \mathrm{~s}$, and a metal-plastic instrument and tweezers were used to remove the sample from the mold. The samples were then examined visually for imperfections. All the specimens were polished using 600 grit sandpaper to remove any coating of lubricant from the surface

\section{Preparation of GCP Samples}

A light-cured GCP (Gloss and Fill, Shade A1; GCP Dental, Vianen, The Netherlands) was available in encapsulated form (Table 1). The inner surface of the mold was coated with GCP gloss. After mixing and activation of the capsule in a Carbomix CM-02 machine (GCP Dental) for $15 \mathrm{~s}$, the material was placed in the mold with slight pressure, and excess from the surface of the mold was removed using a plastic instrument. The entire sample was cured using a high-power Carbo LED curing light for $60 \mathrm{~s}$. After the material was set, it was carefully lifted out of the silicone mold using a metal instrument. The samples were than examined usually for imperfections. All the specimens were polished using 600 grit sandpaper to remove any coating of lubricant from the surface.

\section{Testing of Samples}

A total of 80 samples were prepared and stored at $37^{\circ} \mathrm{C}(100 \%$ relative humidity) and divided into 16 groups ( $n=5$ each) according to time intervals ( $24 \mathrm{~h}$ and 1,2 , and 4 weeks) and the storage medium (artificial saliva and Vaseline). Prior to laboratory testing of the specimens, each sample was measured for dimensional accuracy using a graded micrometer screw gauge (Mitutoyo, Kawa- 
Table 1. Flexural strength $(\mathrm{MPa})$ by material

\begin{tabular}{lccc}
\hline Composition & Mean (SD) & Min to max & 95\% CI \\
\hline Fuji IX (n = 40) & $25.14(13.02)$ & 4.61 to 63.11 & 0.9 to 51.18 \\
$\begin{array}{l}\text { Powder: polyacrylic acid, aluminosilicate glass } \\
\text { Liquid: polyacrylic acid, proprietary ingredient }\end{array}$ & & \\
$\begin{array}{l}\text { Glass carbomer cement }(\mathrm{n}=40) \\
\text { Fill: fluoro-aluminosilicate glass, apatite, polyacids }\end{array}$ & $24.27(12.57)$ & 7.46 to 58.46 & -0.87 to 49.41 \\
Gloss: modified polysiloxanes & & & \\
\hline
\end{tabular}

saki, Japan). The samples were then placed on the Universal Testing Machine (model 5567; Instron, High Wycombe, UK), and a load of $1 \mathrm{kN}$ was applied using a 3 -point bending test $(\mathrm{I}=20 \mathrm{~mm})$ at a crosshead speed of $1 \mathrm{~mm} / \mathrm{min}$ till fracture of the specimen. The readings were recorded with the help of Bluehill 2 modular software (Instron), and flexural strength $(\sigma)$ was calculated using the following formula:

$$
\sigma \frac{3 F l}{2 b h^{2}}
$$

where $\mathrm{F}$ is the maximum load $(\mathrm{N}), \mathrm{l}$ is the distance between the supports on which the sample is placed $(20 \mathrm{~mm}), \mathrm{b}$ is the width of the specimen $(2 \mathrm{~mm})$, and $\mathrm{h}$ is the height of the specimen $(2 \mathrm{~mm})$.

Data were analyzed using Statistica software (Statsoft, Tulsa, OK, USA) using ANOVA and the Tukey post hoc test $(p<0.05)$.

\section{Results}

Table 1 shows the flexural strength value of $25.14 \pm$ 13.02 for Fuji IX, which is $0.87 \mathrm{MPa}$ higher than that of GCP $(24.27 \pm 12.57 \mathrm{MPa})$. The mean flexural strength for samples stored in artificial saliva was $2.36 \mathrm{MPa}$ higher than in Vaseline: $25.89 \pm 14.08$ and $23.53 \pm 11.27 \mathrm{MPa}$, respectively (Table 2 ).

There were no significant differences in flexural strength of FUJI IX and GCP regardless of any solution or storage time. Under artificial saliva, the samples reached a peak flexural strength after 2 weeks for both materials, while the materials showed reduced strength after 4 weeks. In the Vaseline group, the samples showed a homogenous pattern between 24-h and 1- and 2-week time intervals, while 4-week interval samples showed the least flexural strength (Fig. 1).

\section{Discussion}

Glass ionomer-based cements are the material of choice for atraumatic restoration treatment [10] and for restoring cervical dental lesions. They are preferred as
Table 2. Flexural strength (MPa) by storage medium

\begin{tabular}{llllr}
\hline & $n$ & Mean (SD) & \multicolumn{1}{l}{ Min-max } & \multicolumn{1}{l}{$95 \%$ CI } \\
\hline Artificial saliva & 40 & $25.89(14.08)$ & 11.85 to 63.11 & -2.27 to 54.05 \\
Vaseline & 40 & $23.53(11.27)$ & 4.61 to 54.56 & 0.99 to 46.07 \\
\hline
\end{tabular}

they release fluoride and provide chemical adhesion with tooth structure requiring minimal preparation [3]. However, one of the major drawbacks of GIC is their relatively low fracture strength compared to modern resin composite materials [11]. Therefore, the current study assessed and compared the flexural strength of conventional GIC (Fuji IX) with a newly developed GCP. According to the manufacturer, GCP has a higher value of flexural strength than conventional GIC. A study conducted by Gorseta et al. [12] in 2009 showed a flexural strength value of $122.29 \mathrm{MPa}$ for GCP. Another study evaluating the flexural strength of GCP showed values between 9.5 and $10.1 \mathrm{MPa}$ [13]. The methodology adopted by the former study was duplicated in our research and was aimed at determining whether similar results could be obtained. The flexural strength is a commonly evaluated mechanical property of the material as it is more susceptible to showing subtle changes in the substructure than compressive strength tests. Moreover, the flexural strength test produces an appropriate estimate of the tensile strength of the material, thus mimicking the clinical loading situation [2]. Our results indicate that storage media and time intervals had no significant effects on the flexural strength of the cements. Both cements had a uniform pattern of initial increase followed by a decline with respect to time intervals.

Fuji IX showed a mean value for the flexural strength of $25.14 \mathrm{MPa}$ for all samples. A study assessing the flexural strength of GIC showed a mean value of $58 \mathrm{MPa}$ after 2 weeks of storage [14], which is slightly higher than the results achieved at the 2 -week interval in this study. Azil- 
Fig. 1. Effect of different storage media on flexural strength (mean \pm SD) of Fuji IX and GCP at various time intervals. The letters show pairwise significance. The same letters show statistical significance. Small letters indicate significant difference for samples stored in artificial saliva. Capital letters indicate significant difference for samples stored in Vaseline.

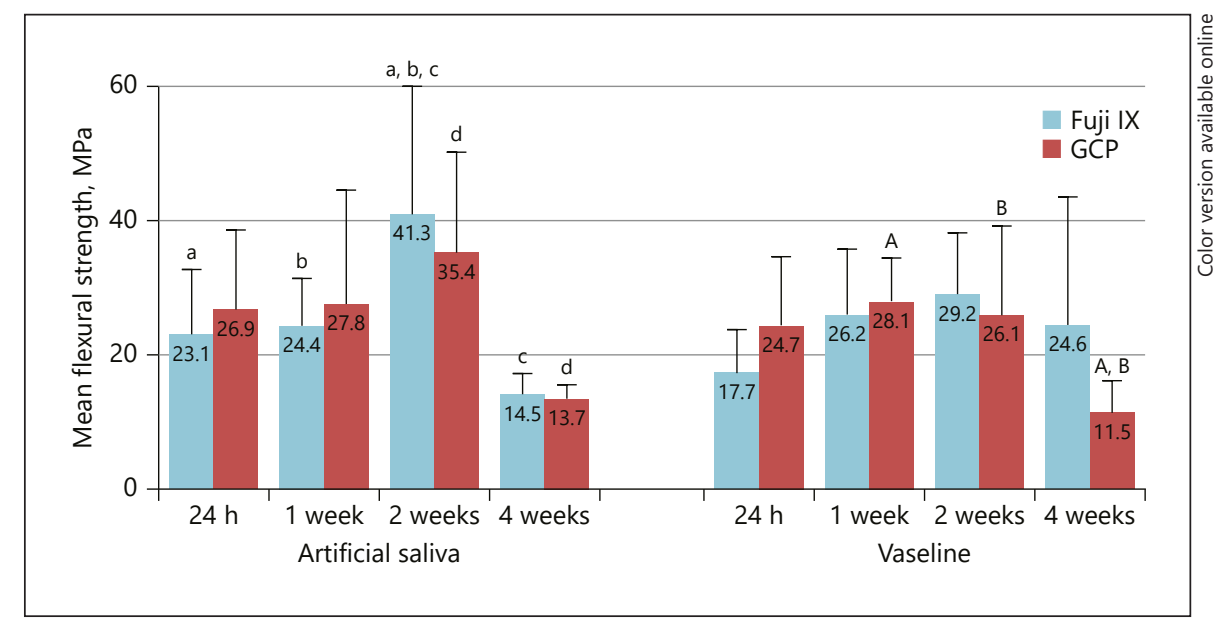

lah et al. [14] suggested that this flexural strength value could be related to the chemical composition of the cement, i.e., the size of the filler particles and the chemical reaction that occurs during setting which causes hydration of the setting matrix and formation of higher-density complex cross-links during the acid-base reaction. Similarly, an experimental study conducted by Prosser et al. [15] showed that the filler particles had a stronger effect on the flexural strength of GIC than the liquid component. Mitra and Kedrowski [16] evaluated the flexural strength of GIC after a storage time of $24 \mathrm{~h}$ and found it to be 14.2-20.5 MPa, which is similar to our results. Similar findings of flexural strength were reported by Xie et al. [17] when they evaluated the various commercially available conventional GIC and found flexural strength values ranging from 21.2 to $31.4 \mathrm{MPa}$. The difference in flexural strength values between various conventional GIC was attributed to dissimilarities in microstructure, denser surface structure, less and smaller voids, and different particle sizes.

GCP showed a mean flexural strength value of 24.27 $\mathrm{MPa}$ for all samples. Three other similar studies were performed previously by other researchers to evaluate the flexural strength of GCP. Two studies conducted by Gorseta et al. [12, 18] in 2009 and 2017 showed flexural strength values of 122.29 and $127.1 \mathrm{MPa}$ for GCP, respectively. According to the authors, these values were attributed to the glass nanoparticles present in the filler of the cement. The other study was conducted by Menne-Hap and Illie [13] in 2013, which showed flexural strength values of GCP between 9.5 and 10.1 MPa after 1 week of storage. One reason cited for the variation in flexural values was the chemical composition of GCP which is free of monomers and contains modified polysiloxanes that cause it to react differently to moisture. However, the composition of GCP in the current study and that by Manne-Hap and Illie [13] was identical. Therefore, the alternative factor could be the use of LED curing light to provide heat during the setting reaction, which was different between the current and their study. Recently, the effect of heat on the mechanical property of GlC was reported by Gavic et al. [19]. They reported increased microhardness of GIC at different depths when thermolight curing was utilized during the initial setting of the material. This improved microhardness can lead to increased flexural strength, thus improving the mechanical properties of the material [19].

The flexural strength of all the samples stored in artificial saliva showed a mean value of $25.89 \mathrm{MPa}$, while samples in Vaseline showed a mean flexural strength value of $23.53 \mathrm{MPa}$. Typically, prior to testing, the samples are stored in aqueous media such as deionized distilled water of high purity [20]. However, this storage medium for GIC is not ideal as it can lead to diminished physical properties due to absorption of water molecules by the cement [20]. Studies have shown susceptibility of the cement to chemical erosion caused by hydrolysis when stored in distilled water [21]. Also, matrix-forming ions are released in the medium to help the process of buffering, thus affecting the strength of the material [20]. Nonetheless, some studies have shown no effect of storage media on the physical properties of the cement. A study conducted by Zoegerbiel and Ilie [22] suggested no significant difference in the flexural strength of GIC when the samples were stored in distilled water and artificial saliva. Another study by Nicholson et al. [23] reported that chemi- 
cal reaction does occur when the cement comes into contact with water, but the effect is minimal.

Ideally, natural saliva should be used as a storage medium as the material is exposed to this medium in the oral cavity. However, studies involving natural saliva have proven to be difficult as the composition of saliva varies between individuals [20]. In addition, bacteria such as Staphylococcus aureus and Staphylococcus albus are more prevalent in patients with caries when compared to caries-free oral cavities [20]. Moreover, the release of enzymes and minerals in the oral cavity varies between individuals and can affect the $\mathrm{pH}$ of saliva [24, 25]. It is for these reasons that, in the current study, artificial saliva was used as one of the storage media as the composition could be controlled considerably, thus anticipating some ion exchange between the cement and artificial saliva resulting in increased flexural strength values. The result of the current study could not be compared with previous studies due to lack of testing of the flexural strength of GCP stored in artificial saliva.

Vaseline is another commonly used surface coating material after placement of restoration to prevent the material from moisture in the oral cavity during initial setting. This initial setting phase can last between $1 \mathrm{~h}$ and 2 weeks, and water contamination during this period may lead to poor physical properties [26]. Hence, Vaseline was tested as a storage medium to evaluate its effect on the materials during different time periods. The effect of Vaseline on GCP has not been studied earlier. The current study suggests that Vaseline did not have any effect on the flexural strength of GIC and GCP.

Storage of samples for 2 weeks showed the highest flexural strength, while samples stored for 4 weeks showed the lowest flexural strength. It has been shown that the strength of GIC reaches its peak in the first $24 \mathrm{~h}$ followed by a gradual decrease over time [14]. This increase in strength could be attributed to the formation of more ionic crosslinks during acid-base reaction in the final setting of the material, while the decrease in strength could be related to the hydration of these ionic crosslinks. A study conducted by Walls et al. [27] evaluated the temperature changes in GIC during the setting reaction. They concluded that the rise in temperature during mixing is responsible for the setting time of the cement. This can be directly related to the composition of glass present in the cement as it can affect the exothermic reaction leading to faster setting times and thus reaching optimum strength at an early stage [28].

Other factors that might have influenced the strength of the samples are the different methods of dispensation and mixing for Fuji IX and GCP. Fuji IX was available in powder and liquid form and was mixed manually, while GCP was present in encapsulated form and was mixed with the help of a triturator. Billington et al. [28] suggested that the properties of the materials are altered if they are not mixed properly. A survey showed that many dental practitioners did not follow the mixing ratio specified by the manufacturer [29], while another study showed that the strength of the cement was higher for the encapsulated form than for hand-mixed GIC [30]. Another factor affecting the strength could be the viscosity of the materials used in this study. GCP is highly viscous; therefore, achieving a uniform and homogenous sample was difficult, while Fuji IX flowed easily under pressure and resulted in more uniform samples.

\section{Conclusion}

The following conclusions can be drawn from this in vitro study: contrary to the claims of the manufacturer of improved flexural strength for GCP, both materials demonstrated similar results in this study. Therefore, their use should be limited where flexural stresses are low. Storage media do not provoke any significant difference in flexural strength at any time interval. The 2 -week time interval showed the highest values for flexural strength, while the 4 -week interval showed the least values. Further testing in the form of in vivo studies and randomized controlled trials are required to explore the true potential of GCP.

\section{References}

1 Lesage BP: Aesthetic anterior composite restorations. A guide to direct placement. Dent Clin North Am 2007;51:359-378.

2 Lohbauer U: Dental glass ionomer cements as permanent filling materials? - Properties, limitations and future trends. Materials 2010; 3:76.
3 Sidhu SK, Nicholson JW: A review of glassionomer cements for clinical dentistry. J Funct Biomater 2016;7:16.

4 Cehreli SB, Tirali RE, Yalcinkaya Z, et al: Microleakage of newly developed glass carbomer cement in primary teeth. Eur J Dent 2013;7: $15-21$.
5 Jayanthi N, Vinod V: Comparative evaluation of compressive strength and flexural strength of conventional core materials with nanohybrid composite resin core material an in vitro study. J Indian Prosthodont Soc 2013;13:281289. 
6 Khoroushi M, Keshani F: A review of glassionomers: from conventional glass-ionomer to bioactive glass-ionomer. Dent Res J (Isfahan) 2013;10:411-420.

7 Van Duinen RNB, Davidson CL, De Gee AJ, et al: In situ transformation of glass-ionomer into an enamel-like material. Am J Dent 2004; 17:223-227.

8 Moshaverinia A, Ansari S, Moshaverinia N, et al: Effects of incorporation of hydroxyapatite and fluoroapatite nanobioceramics into conventional glass ionomer cements (GIC). Acta Biomater 2008;4:432-440.

9 McCabe JF, Walls AWG: Properties used to characterize materials; in McCabe JF, Walls AWG (eds): Applied Dental Materials, ed 9. Oxford, Blackwell, 2009.

10 Honkala E: Primary oral health care. Med Princ Pract 2014;23:17-23.

11 Bonifácio C, Kleverlaan C, Raggio D, et al: Physical-mechanical properties of glass ionomer cements indicated for atraumatic restorative treatment. Aust Dent J 2009;54:233237.

12 Gorseta K, Vrani DN, Glavina D, et al: Effects of polymerisation unit on the flexural strength of glass carbomer. Int J Paediatr Dent 2009; 19(suppl 1):75.

13 Menne-Happ U, Ilie N: Effect of gloss and heat on the mechanical behaviour of a glass carbomer cement. J Dent 2013;41:223-230.

14 Azillah MA, Anstice HM, Pearson GJ: Longterm flexural strength of three direct aesthetic restorative materials. J Dent 1998;26:177182.
15 Prosser HJ, Powis DR, Wilson AD: Glass-ionomer cements of improved flexural strength. J Dent Res 1986;65:146-148.

16 Mitra SB, Kedrowski BL: Long-term mechanical properties of glass ionomers. Dent Mater 1994;10:78-82.

17 Xie D, Brantley WA, Culbertson BM, et al: Mechanical properties and microstructures of glass-ionomer cements. Dent Mater 2000;16: 129-138.

18 Gorseta K, Borzabadi-Farahani A, Moshaverinia A, et al: Effect of different thermo-light polymerization on flexural strength of two glass ionomer cements and a glass carbomer cement. J Prosthet Dent 2017;118:102-107.

19 Gavic L, Gorseta K, Borzabadi-Farahani A, et al: Influence of thermo-light curing with dental light-curing units on the microhardness of glass-ionomer cements. Int J Periodontics Restorative Dent 2016;36:425-430.

20 Mckenzie MA, Linden RWA, Nicholson JW: The physical properties of conventional and resin-modified glass-ionomer dental cements stored in saliva, proprietary acidic beverages, saline and water. Biomaterials 2003;24:40634069 .

21 Lorente MA, Godin C, Meyer JM: Mechanical behavior of glass ionomer cements affected by long-term storage in water. Dent Mater 1994; 10:37-44.

22 Zoergiebel J, Ilie N: Evaluation of a conventional glass ionomer cement with new zinc formulation: effect of coating, aging and storage agents. Clin Oral Investig 2013;17:619626.
23 Nicholson JW, Mckenzie MA, Goodridge R, et al: Variations in the compressive strength of dental cements stored in ionic or acidic solutions. J Mater Sci Mater Med 2001;12:647652.

24 Chauncey HH, Lionetti F, Lisanti VF: Enzymes of human saliva. J Dent Res 1957;36: 713-716.

25 Whitford GM, Thomas JE, Adair SM: Fluoride in whole saliva, parotid ductal saliva and plasma in children. Arch Oral Biol 1999;44: 785-788.

26 Kamatham R, Reddy S: Surface coatings on glass ionomer restorations in pediatric dentistry - worthy or not? J Indian Soc Pedod Prev Dent 2013;31:229-233.

27 Walls AWG, Mccabe JF, Murray JJ: Factors influencing the setting reaction of glass polyalkenoate (ionomer) cements. J Dent 1988;16: 32-35.

28 Billington RW, Williams JA, Pearson GJ: Variation in powder/liquid ratio of a restorative glass-ionomer cement used in dental practice. Br Dent J 1990;169:164-167.

29 Iqbal K, Islam SA, Ahmad I, et al: Variations in powder/liquid ratio of a restorative and luting glass ionomer cement in dental clinics. J Coll Physicians Surg Pak 2009;19:464-465.

30 Dowling AH, Fleming GJ: Are encapsulated anterior glass-ionomer restoratives better than their hand-mixed equivalents? J Dent 2009;37:133-140. 